\title{
O SORRISO KAFKIANO DE FOUCAULT
}

\author{
THE KAFKIAN SMILE OF FOUCAULT
}

\author{
Daniel de Oliveira Gomes* \\ Universidade Estadual do Centro-Oeste do Paraná - UNICENTRO, BR
}

\begin{abstract}
RESUMO: O presente artigo investiga uma relação entre Foucault e Kafka pontuando o tema autoral da "renúncia de si”, ou do “apagamento de si”. Tal desaparecimento se dá de modo distinto de casos como as máscaras de Fernando Pessoa ou como o apagamento do inventor no âmbito da Renascença. Mesmo assim, Foucault sorri como Mona Lisa, de Leonardo Da Vinci, imagem de Durval Albuquerque Júnior, e neste riso de nós e de si mesmo, abre-nos pistas para que possamos imaginá-lo dentro de sua obra. Uma obra que evolveu o problema da autoria de tal modo que atingiu a revisão do conceito helenístico do "cuidado de si”, em sua última fase.
\end{abstract}

PALAVRAS-CHAVE: Foucault; Kafka; pessoa; Da Vinci; cuidado de si.

ABSTRACT: This article investigates a relationship between Foucault and Kafka punctuating the authorial theme of the "selfdenial," or "self-effacement." This disappearance occurs differently from cases like the masks of Fernando Pessoa, or as the effacement of the inventor in the Renaissance. Even so, Foucault smiles like Mona Lisa, by Leonardo Da Vinci, image of Durval Albuquerque Júnior, and this laugh at us and at himself opens up clues to us so we can imagine him inside his work. A work that evolved the authorship issue in such a way that affected the Hellenistic concept's review of the "self- care" in his last phase.

KEYWORDS: Foucault; Kafka; person; Da Vinci, self-care.

Aprisionados pela ordem dos discursos e suas instituições, como ele foi um dia, continuamos tentando decifrar os signos emitidos por seus escritos e por seu rosto, que em muitas fotografias, como uma Mona Lisa de Da Vinci, nos contempla com um sorriso misterioso e zombeteiro, nos desafiando a procurar nos aproximar de seu segredo, mesmo tendo aprendido com ele que na raiz dos textos está a dispersão dos arquivos e artimanhas das forças e que o segredo dos sujeitos é a multiplicidade das máscaras. (ALBUQUERQUE JR., 2006, p.97)

O que faz Michel Foucault, metodologicamente, haja vista a contribuição de sua escritura e de seus exames pelo campo lingüístico e das Teorias da Literatura, é, de algum modo, reavivar e repolitizar debates préformalistas que apontavam o rito do escritor em sua especificação como centro de espetáculo, mostrando o quanto é recente este estatuto. No clássico "A Ordem do Discurso", por exemplo, como em outros tantos textos, o filósofo lembra a questão dos "direitos autorais" e de como o seu aparecimento fortalece este código da "afirmação do eu". Sabemos, entretanto, que nem todo autor moderno adere a este rito. Sequer Foucault adere a este rito. Em 82, em entrevista ao Sr. Martain, da Université Du Vermont, Foucault mesmo disse:

No creo que sea necesario saber exactamente lo que soy. En la vida y en trabajo lo más interesante es convertirse en algo que no se era al principio. Si se supiera al emprezar un libro lo que se iba a decir al final, ¿cree usted que se tendría el valor para escribirlo? Lo que es verdad de la escritura y de la relación amorosa también es verdad de la vida. El juego merece la pena en la medida en que no se sabe cómo va a terminar. (FOUCAULT, 2000, p.142)

Pense-se, igual modo, em casos paradoxais como a escrita experimental de Breton; ou, melhor ainda, pensese no processo múltiplo que vem a ser a heteronímia pessoana, orientada não apenas por uma ansiedade vanguardista, mas por um problema mais ontológico. Em Pessoa, a título de um bom exemplo do cuidado e da renúncia de si, não podemos postular o drama heteronímico como simples máscara, onde atrás repousaria uma identidade prestes a ser resgatada, mas sim a fuga de polarizações maniqueístas (razão\&emoção) que já são colocadas em conflito de alteridade desde um autor que Pessoa considerava superior a Camões: Antero de Quental. Uma mesma ferida ontológica, por assim dizer, é repartida entre Pessoa e Antero. Indo um 
pouco mais longe ainda, lembro Ettore Finazzi-Agró que já dizia, certa vez, que os heterônimos manifestam-se desde o romantismo e mesmo antes do séc. XVII. Ou seja, a questão da renúncia de si, que aqui pretendo observar em Foucault, é uma velha questão de apagamento mas não bem como os de Pessoa e Antero. O transcendentalismo metafísico de Antero talvez ainda seja utópico, sob influência alemã, hegeliana, enquanto Pessoa já é atópico, sua pátria era sua língua - ou como postulava Leyla Perrone Moisés - a identidade, o si mesmo, em Pessoa é algo complicado quando ele em si mesmo vem a ser um país descoberto e redescoberto tantas vezes. A questão da renúncia de si, associada à Foucault, que aqui gostaria de tratar, é de outro calibre, eu diria uma renúncia mais kafkiana. Não se trata tanto de uma eliminação excessiva pelo auto-desaparecimento, confusão de luz e sombras, contexto muito dolorido de fingimento onde quem se descontextualiza não é o eu-lírico, mas a realidade ao seu entorno. Foucault não é lá um sujeito em crise de identidade, a meu ver. Um sujeito em crise de identidade geralmente deve ser dramático como Pessoa e não tão sorridente quanto Foucault.

Dentre muitas outras exemplificações literárias ou filosóficas da despersonalização, ou do anonimato autoral, quero pensar aqui na publicação de rascunhos como os de Kafka, se não fosse uma presença outra a de Max $\operatorname{Brod}^{1} \ldots$ ou se não fosse o modo como os franceses releram Kafka, onde este encontraria sua comunidade negativa? Qual seja, de que modo Kafka poderia evaporar-se como assinatura de suas obras, se não por meio de vozes outras, vozes amigas, enfim, como poderia perder-se em sua própria dissipação de si?

Há um paradoxo no modo como Foucault nos convida a lê-lo, a achá-lo, qual seja, no modo como o autor ri de nós e de si mesmo oferecendo-nos pistas para que possamos pensar que o encontraremos seguramente no interior de seus escritos, ou através deles. Foucault sorri como Gioconda enquanto Kafka destrói a função do aplauso, da aprovação, da adesão a qualquer contemplação de si, vindo a renunciar-se como possibilidade de espetáculo que é o que justamente na filosofia pós-estrutural ou pós-utópica (Blanchot e Bataille) se configurará historicamente: Kafka-modelo. Nesse sentido, há uma graça enigmática entre Kafka e Foucault. Durval Muniz de Albuquerque Júnior, em um criativo artigo, nos diz:

As obras de Foucault nos interpelam como o sorriso de Mona Lisa, para que desvendemos os seus segredos, ao mesmo tempo em que já riem desta pretensão, quando ele mesmo nestas obras arruinou as categorias com as quais poderíamos fazê-lo: autor, obra, comentário, verdade, método, nada escapou de sua cortante ironia. Seus textos, como o famoso quadro de Da Vinci, já deram origem a inúmeras leituras, que seguiram as inúmeras e contraditórias pistas que deixou, sem conseguir aprisioná-lo em uma identidade. Ele nunca foi o mesmo. (2006, p.104)

Kafka torna-se arquétipo de uma recusa de si que fecunda uma comunidade da negatividade contra a corrente de seu tempo; e assim sendo o faz de modo diferente de como esta recusa de si se dava em outros momentos mais remotos, como, por exemplo, no Renascimento, para tomar aqui a imagem acima de Leonardo Da Vinci.

Sabemos que, nos séculos XV e XVI, o conceito de mimese estava atrelado a uma renúncia da própria personalidade do sujeito-artista, tal renúncia de si seria uma vantagem e não um defeito para engenhosidade fecunda da época. A concepção de personalidade artística como a conheceu hoje - já nos explicava Mukarovsky, confinante ao círculo Lingüístico de Praga - nasceria apenas no séc. XIX, de modo que não podemos dizer que as obras ou invenções do período renascentista, por exemplo, sejam produtos, propriamente, de uma personalidade artística deliberada. A noção de personalidade artística, aliás, era muito mais quantitativa do que qualitativa, neste período. Veja-se o desempenho inventivo de Da Vinci, não apenas na perfeição estética dos traços enigmáticos no sorriso de Gioconda, mas também em todas suas invenções mais objetivas, como anatomista, por exemplo. Anatomista em seus quase desconhecidos e bizarros desenhos de estudo de cadáveres humanos, onde o miscigenado caráter morfológico, antropométrico e simbólico do corpo encontrava uma forma embrionária já ali na Renascença. Da Vinci possui relevantes desenhos oriundos de estudos tanto do mecanismo da copulação humana, quantos estudos das proporções ósseas, dos sistemas vascular e nervoso, algo que, claro, não chamaríamos moderna e efetivamente de "scienza", mas sim de um desdobramento curioso de filosofia natural e estética, onde o

\footnotetext{
Italo Moriconi, no ensaio “O espectro de Foucault”, nos recorda que “(...) dizem que quando vivo Foucault criticava a atitude de Max Brod. Para ele, só deveria ter prevalecido a vontade de Kafka, o autor. Se este quisera ter seus escritos destruídos depois de morto, era isso que o amigo Brod deveria ter feito." (2007, p.179).
} 
espírito da arte e a filosofia do corpo (a medicina) caminhavam juntas, de mãos dadas, na focalização dos cadáveres. Descoberta física dos homens.

Enquanto a sociedade ocidental aposta, desde o advento do cristianismo e suas técnicas de controle da carne, em aprender e apreender as diferenças essenciais entre alma e corpo, no célebre "A Hermenêutica do Sujeito", texto marcante de Foucault acerca do "epimeleîsthai heautoû" (o cuidar de si), o filósofo, por sua vez, remete ao contexto helenístico. Neste, a tarefa primordial da prática de si está no de-discere, no desaprendizado. Além disso, defende o combate constante que é preciso para cuidar de si, que está em dois aspectos conjuntos, o físico (atlético, corpo) e a alma (guerra, sentimento). A função de ser soberano de/em si mesmo seria mais terapêutica, curativa, do que efetivamente utilitária ou pedagógica. Viajará por séculos para relembrar do moralista grego Plutarco, que afiançava a medicina e a filosofia como sinais de um apenas domínio.

Hay que recordar también el principio familiar para los epicúreos, los cínicos y los estoicos de que el papel de la filosofia es curar las enfermidades del alma. Plutarco llegará a decir que la filosofia y la medicina constituyen mia khóra, uma única región, um solo domínio. (FOUCAULT, 1996, p.39)

A idéia do cuidar de si, para que possamos pensar a questão paralela da renúncia do ego no âmbito especificamente literário ou escritural foucaultiano e kafkiano, está associada ao páthos (alma e corpo, sentimento e doença). Não se trataria de cuidar-se de si mesmo de modo estratégico tão somente para não cair em emboscadas, perigos do corpo ou da alma, e sim seria um dever fundamental do concidadão, sob um conjunto de procedimentos complexos em busca de uma vida saudável. Esta vida saudável se apresenta na relação cuidadosa de si consigo. Não poderia mais, aqui, interpretar o corpo de modo cartesianamente dualista, corpo versus alma, recaindo na velha dificuldade com a qual nossa memória, desde Platão, observa a noção de corpo como um sentido, "tumba da alma". Não é a distinção com a alma o que realça Jean-Luc Nancy, em seus "58 indícios sobre o corpo", ao procurar definir o corpo inoperantemente, como apagamento, excesso de sentido (outrance), corpo como força diferencial entre outros corpos... Nesse sentido, o corpo, a carne, o sorriso, é, assim, acima de tudo, contraste. O sorriso seria uma possessão, não me aproprio do corpo, do sorriso do corpo, expressado pela face, eu o possuo e sou, igual modo, possuído por meu corpo e seus gestos. O corpo é sempre fragmentado, para Nancy. Um sorriso é, igual modo, sempre fragmentado. O de Michel Foucault é fragmentado em excesso. Nem tanto o sorriso perdido de Pessoa, em seu múltiplo, "esquizo", amplo e irreverente tom de obscuridade, mas o sorriso acastelado de Kafka. Sorriso microfísico. (Hibridismos cuidadosos em cada dente.)

Aqui, entra a postura patológica do sorriso saudável e também clandestino do autor em quase todas as fotografias em que ele figura. Um sorriso grande, graúdo, que, conforme Albuquerque Júnior era em alto grau irônico, mordaz: por um lado sugerindo divertidamente que devemos o descobrir, por outro, dizendo belicamente para jamais perguntar quem ele era afinal. Sorriso do guerreiro, daquele que estava sempre preparado para luta. Além de associada a um eterno combate, a idéia de cuidar de si é também adjunta a um ideal de desfrutar-se de si mesmo, exploração infinita de sua própria voluptuosidade pessoal, criativa, sorridente e transformadora. De modo que a epiméleia não é apenas a consciência de si, a atenção a si, mas designará, sim, uma determinada ocupação inventiva que contesta o que, a priori, penso ser o "eu mesmo". Uma prática do retiro (anacoresis) pelo sorriso da palavra, ou, melhor dizendo, de prática de escritura indissociável da vida que (oposto à uma simples renúncia moral de si, do corpo, dos prazeres, em nome de verdades exteriores) modifica o modo de ser para torná-lo ethopoiético, arte de ser. Sorriso sem culpas.

Pablo Perera Velamazán, no artigo "Pensar de outro modo: Dos variaciones em torno a Michel Foucault", recorda em certo momento a renuncia de si de Kafka e mostra-a atrelada ao trabalho clandestino de Foucault, pelo viés crítico de Maurice Blanchot:

Maurice Blanchot, siempre tan cercano a Foucault, comentando la obra de Kafka, refería acerca de la soledad del escritor que, atado a su mesa de trabajo, 'mientras que sus semejantes disfrutan com inocencia de la vida', se percibe como um ser al margen de todo, casi clandestino: 'escribir es ponerse fuera de la vida' concluye Blanchot. También podemos remitirlas a la imagen de Foucault encerrado durante días en uma biblioteca, siempre sentado en el mismo sitio, leyendo o copiando archivos, al margen de su tan comentada vida pública, como um personaje de Borges que se dedica a buscar semejanzas. Y es que solo um pensamiento, que es siempre una forma de escritura como muy bien enseñó Blanchot a Foucault, un pensamiento com vocación solitaria y clandestina, al margen de cualquier proceso de legitimación de lo ya-dado, es capaz de tramar estratégias sobre su próprio despliegue, de ‘pensarse a si mismo’. (VELAMAZÁN, 1996, p.109) 
Velamazán resgata uma imagem não apenas da filosofia marginal do autor, a vocação solitária que sai vida a fora em busca da legitimação do que já se sabe. Mas, sim, a blanchotiana imagem daquele corpo à margem de Foucault, fora da própria vida, no patológico processo de eterna busca de si, pela pesquisa solitária, pelo reino dos arquivos, que também é renúncia do eu (qual Kafka). Foucault, com efeito, buscava não apenas legitimar o já-dado, mas tornar viável uma experiência aberta do presente diante de sua própria contingência (Veja: VELAMAZÁN, 1996, p.116).

Se Kafka não quis publicar a carta que fez ao seu pai (Brief an den Vater), em novembro de 1919, então, de algum modo, ele nega a sua capa de monstro-parricida com a qual destrói toda moralidade de Hermman Kafka. Esta malquerença do/em nome do pai está, ali, como exemplo de recusa solitária de si. Recusar-se a si mesmo, neste instante, é uma recusa do lugar do próprio pai o qual evita ocupar, o lugar da autoridade, como dirá Bataille. A gargalhada infantil de Kafka está nesta negação, nesta premissa ética.

L'attitude de Kafka veut être maintenant précisée, et son caractère extrême accusé. Non seulement, il devait être reconnu de l'autorité la moins susceptible de le reconnaître (puisque - il y était résolu sans réticences - il ne céderait pas), mais il n'eut jamais l'intention d'abattre cette autorité, pas même de s'y opposer. Il ne voulut pas s'opposer à ce père qui lui retirait la possibilité de vivre, il ne veut pas être, a son tour, adulte et père. A sa manière, il mena une lutte à mort pour entrer dans la société paternelle avec la plénitude de ses droits, mais il n'aurait admis de réussir qu'à une condition, rester l'enfant irresponsable qu'il était. (BATAILLE, 1957, p. 115)

O espaço da autoridade cede lugar a uma dada irresponsabilidade na recusa de si, uma aventura pueril, que é a da própria solidão, a da própria escritura. Sabidamente, Michel Foucault, também tinha determinada rivalidade com seu pai e, quando começa a ler Hegel, Kant, Heidegger, Marx e Freud, começando a se aventurar na produção de seus primeiros esboços textuais (seus primeiros sorrisos filosóficos), ele resiste cada vez mais kafkianamente à sphère paternelle. Após decidir que nada queria com o campo da medicina, o adolescente Michel Foucault retirava o nome "Paul" de sua assinatura, que o assemelhava ao seu pai (Paul Foucault). Então, aos dezessete anos de idade, resolvia por estilhaçar qualquer reminiscência dos tradicionais cirurgiões da família Foucault, inclinando-se para um caminho distinto de seu avô e, sobretudo, de seu pai. Este adolescente que nada ansiava com o universo clínico, que ria dos médicos, irá, justamente, transformar sua caneta em bisturi, movimento de uma obra em marcha que Philippe Artières chamará de “um gesto de cirurgião".

Michel Foucault revela que seu estilo provavelmente vinha de uma antiga herança do bisturi: ' Talvez eu
trace sobre a brancura do papel os mesmos sinais agressivos que meu pai outrora traçava sobre os
corpos quando ele operava, Eu transformei o bisturi em porta-caneta'. O filósofo prossegue comparando
sua atividade à do anatomista fazendo uma autópsia. Com sua escrita ele percorria o corpo do outro,
cortava-lo erguia os tegumelos e a pele, tentava descobrir os órgãos e, diz ele, 'atualizando os órgãos,
fazer aparecer o núcleo da lesão, o núcleo do mal, algo que caracterizou sua vida, seu pensamento e que,
em sua negatividade, por fim organizou tudo o que eles foram'.

Com efeito, tudo se passa como se, pela descrição do olhar da anatomia patológica, a de Bichat, se desvelasse o autorretrato do intelectual Foucault que, engajado em uma série de lutas alguns anos depois, produz diagnósticos por uma série de olhares de médico sobre o acontecimento que se desenvolve sobre seus olhos.

Foucault nunca deixou de refinar em seus livros essa prática de cirurgião. (ARTIÈRES, 2002, p.28)

O adolescente ria dos médicos, porém, nesta busca por diagnósticos de certos acontecimentos filosóficos, Foucault cresce e acaba produzindo e defendendo, no início dos anos 60, sua tese doutoral na Sorbonne "A História da Loucura na Idade Clássica”, que desencadeia em imediato sucesso, posto que um ano depois conheça Deleuze e adentre para o conselho de redação da "Critique", revista fundada por nada menos que Georges Bataille. Certamente um dos momentos muito felizes de Foucault, ocasião em que, ainda três anos antes de “As Palavras e as Coisas”, estará a publicar "O Nascimento da Clínica”. Aqui, longas perguntas se sucederão sobre o tema do artigo, a recusa de si: Em Foucault, como pode operar, ou fazer sentido, esta recusa primária de si (como fuga do campo médico), se o que leva Foucault a um renome filosófico acaba por ser seu inevitável interesse pelo tablado de seu pai (Paul Foucault)? A remoção do "Paul” possui qual sentido, senão meramente inexplicável como recusa de si, quando ao se engajar no campo da medicina, Foucault aponta vários desprendimentos, em busca de uma arqui-genealogia talvez não apenas do sujeito histórico, mas de si próprio? 
Outra pergunta que faço: o que entraria em pauta, em seu próprio fazer autoral, nas formas de subjetivação que Foucault estudou desde o período helenístico, passando pelos romanos e o período de instrumentalização da moralidade cristã? Tento responder. Além da sustentação de uma resistência ou um certo movimento de contra-vigilância do sujeito em uma era dos biopoderes - o que entraria em cena seria a própria constituição da existência de uma assinatura sorridente de Michel Foucault, ao longo de sua obra. O sorriso do anatomista. Enfim, à luz do último Foucault, talvez não possamos dizer onde especificamente se afirma o sujeito-autor Foucault em toda sua obra. Apenas sabemos de uma longa e profunda coerência em todos os três andamentos nas diretrizes que o próprio Maurice Florence (Foucault e Ewald) classifica, no dicionário lançado em 1981, em Paris. (Não é como Barthes que possui duas ou várias faces antagônicas, um tempo marcadamente estruturalista, semiológico, outro não).

Propondo que não se trata propriamente da busca de um novo código e sim de interrogar o enigma com o qual o sujeito se constitui filosoficamente no ocidente, o que fala sobre a ontologia do presente, desde Foucault, é antes um desmantelamento identitário (Maurice Florence?), não é o próprio autor. Não é tanto uma questão da afirmação ou negação da verdade do sujeito, mas de vislumbrar de modo infra-intelectual, hilariante, a questão dos jogos de verdade, e que já está presente desde os estudos arqueológicos do autor.

Aquí uno há de tener cuidado: negar el recurso filosófico de um sujeto constitutivo no equivale a comportarse como si el sujeto no existiera ni dejarlo totalmente de lado em favor de uma objectividad pura. El propósito de esta negativa es sacar a la luz los processos adecuados de uma experiencia por la cual sujeto y objeto 'se forman y transforman ellos mismos' en su relación y función mutua. (FLORENCE, 1996, p.7)

O sorriso de Foucault não é o retrato de uma infantilidade que não seja kafkiana. Foucault não permanece em um sítio afirmativo que não seja o da própria renúncia de si: Foucault que era considerado marxista, mas nem tanto, não desejava o ser; Foucault que era considerado ativista, mas nem tanto, não desejava o ser; Foucault que não era nem tanto um historiador ou filósofo, entretanto, ao modo de um Da Vinci, era mais considerado um artista, um filósofo-diagnosticador, um anatomista, um médico-escriba do presente, um louco rangendo... Como bem dirá Edson Passeti: "Foucault range por si, louco, raposa, terceiro, último, um único Foucault, homem e pensador que não se deixou apanhar por representações, nem descansa em ninhos universitários" (PASSETI, 2006, p.109, 110). Philippe Artières inicia seu texto "Dizer a Atualidade: o trabalho de diagnóstico de Michel Foucault" citando o termo "diagnóstico" do dicionário francês do sec. XVIII, de Petit Robert: "diagnóstico é a ação de determinar uma doença segundo seus sintomas". Se Foucault considerava a si próprio um diagnosticador do presente rumo uma ontologia da agoridade, a última fase temática (pratique de sol) de sua obra não é uma fase cujos sintomas são totalmente inéditos levando em conta sua obra geral como "enfermidade" filosófica. Creio que é, sim, a teorização de qualquer coisa, paradoxal na era moderna, que Foucault sempre pôs em prática incessantemente. Seria a renúncia da medicina? Seria o sorriso da renúncia de si?

O que o último Foucault poria em movimento, como algo inovador, seria a ação de auto-diagnóstico de uma patologia do desejo que estaria desde a origem em seu próprio fazer filosófico. Sorriso auto-irônico. Blandine Kriegel em seu livro "Michel Foucault aujourd'hui” postula, em certo capítulo, o "Foucault artista”, mesmo contra a visão do próprio Foucault. Certa ocasião, Foucault teria recusado dedicar um livro a um admirador, protestando que apenas os artistas autografam suas obras. Teria dito "Je ne suis pas un scientifique et je ne suis pas un artiste." Porém, Blandine Kriegel questiona veementemente "Je sais qui je ne suis pas? Qui etait-il allors?". (KRIEGEL, 2004, p.45.).

Se Pessoa não era nada ao produzir heterônimos que, no fundo, são um mesmo autor a dizer "eu sou isto, eu sou aquilo, eu sou isto, eu sou aquilo"; Kafka e Foucault, aqui reflito, não são nada quando dizem invariavelmente "eu não sou isto, eu não sou aquilo...". Recordo, uma vez mais, que para o sujeito-artista, em meados da Renascença, séc. XVI, a recusa de si mesmo dava-se, repetimos, como uma vantagem e não como um defeito para engenhosidade fecunda. Os grandes gênios da Renascença, na qualidade de maiores inventores da história, já nasciam como personalidades expungidas ante suas próprias descobertas e invenções, suas obras eram as fontes de iluminação que os ofuscava. O sorriso da invenção era um poder maior do que o sorriso do inventor. Já no caso de Kafka, já no caso de Foucault, para recusar-se a si mesmo como "auctor", o artista precisa apagar-se contra a luz de seu próprio tempo, e não apenas contra a luz de suas obras. Todo modo, Foucault continua a sorrir e multiplicar sorrisos, de modo que aqui finalizamos este texto com uma cita de Durval Muniz Albuquerque Jr., sobre Foucault e seu sorriso à Mona Lisa: 
Aprisionados pela ordem dos discursos e suas instituições, como ele foi um dia, continuamos tentando decifrar os signos emitidos por seus escritos e por seu rosto, que em muitas fotografias, como uma Mona Lisa de Da Vinci, nos contempla com um sorriso misterioso e zombeteiro, nos desafiando a procurar nos aproximar de seu segredo, mesmo tendo aprendido com ele que na raiz dos textos está a dispersão dos arquivos e artimanhas das forças e que o segredo dos sujeitos é a multiplicidade das máscaras. (ALBUQUERQUE JR., 2006, p.97)

\section{REFERÊNCIAS}

ALBUQUEQUE Jr. Durval Muniz. Michel Foucault e a Mona Lisa ou Como escrever a história com um sorriso nos lábios. In: RAGO, Margareth; VEIGA-NETO, Alfredo (Orgs.). Figuras de Foucault. Belo Horizonte: Autêntica, 2006.

ARTIÈRES, Philippe. Dizer a atualidade. O trabalho de diagnóstico em Michel Foucault. In: GROS, Frédéric (Org.). Foucault a coragem da verdade. São Paulo: Parábola, 2004.

BARTHES, Roland. A morte do autor. In: O rumor da língua. Tradução de Antônio Gonçalves. Lisboa: Edições 70, 1984.

BATAILLE, Georges. Kafka. In: La Littérature et le mal. Paris: Gallimard, 1957.

BLANCHOT, Maurice. O Espaço Literário. Trad. Álvaro Cabral. Rio de Janeiro: Rocco, 1987.

FLORENCE, Maurice. Foucault, Michel, 1926 (-1984). Revista de Filosofia anábasis, Madrid, ano 3, n. 4, 1996.

FOUCAULT, Michel. La hermenêutica del sujeto. Conclusiones de los cursos 1980-1982. Revista de Filosofia anábasis, Madrid, ano 3, n. 4, 1996.

GOMES, Daniel de Oliveira; SOUZA, Pedro de (Orgs.). Foucault com outros nomes. Lugares de enunciação. Ponta Grossa: UEPG, 2009.

KRIEGEL, Blandine. Foucault, artiste. In: Michel Foucault aujourd'hui. Paris: Editions Plon, 2004.

PASSETI, Edson. Heterotopia, anarquismo e pirataria. In: RAGO, Margareth; VEIGA-NETO, Alfredo (Orgs.). Figuras de Foucault. Belo Horizonte: Autêntica, 2006.

VELAMAZÁn, Pablo Perera. Pensar de otro modo: dos variaciones en torno a Michel Foucault. Revista de Filosofia anábasis, Madrid, ano 3, n. 4, 1996.

Recebido em 11/07/11. Aprovado em 04/02/12. 